\title{
UnCERTAinty OF Surface Measurement
}

\author{
Dana Kubátová, Martin Melichar
}
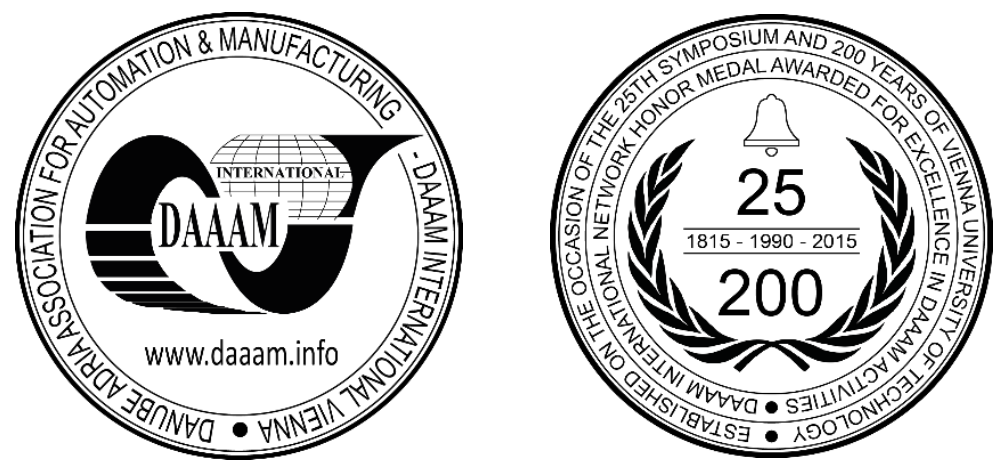

This Publication has to be referred as: Kubatova, D[ana] \& Melichar, M[artin] (2018). Uncertainty of Surface Measurement, Proceedings of the 29th DAAAM International Symposium, pp.1239-1248, B. Katalinic (Ed.), Published by DAAAM International, ISBN 978-3-902734-20-4, ISSN 1726-9679, Vienna, Austria DOI: $10.2507 / 29$ th.daaam.proceedings. 179

\begin{abstract}
Article describes methodology and practical use of measurement uncertainties. Measurement uncertainties are an integral part of all higher measurement systems and are used in all accredited testing or calibration laboratories, including official measurements as a mandatory output and part of the measurement results. Article in the first part summarizes the theory on this issue. Then follows the practical use of these uncertainties when measuring surface roughness for parameters Ra, Rz, Rv and Rsm. This includes recording changes to the type of software filter used. As can be seen from the outputs, the measurement uncertainty plays a large role in determining the measurement results and potentially can significantly affect the measured values on one or the other side of the result.
\end{abstract}

Keywords: uncertainties; type of uncertainty; measuring; roughness; statistical calculations

\section{Introduction}

Knowledge of possible causes of process variability is fundamental to any measurement. In measuring, process variability is referred to as errors of measurement. Errors or measurement are expressed using uncertainties of measurement. In order to process the results of measurement of tests of selection of software filters, a procedure for calculating their uncertainty had to be established with respect to their specifics. For this reason, the chapter Errors and Uncertainties of Measurement was included in this article. According to Werner Heisenberg and his uncertainty principle, a measuring instrument improved beyond perfection still fails to deliver absolutely accurate results because some errors will always be present. [1]

"Measurement is a set of experimental tasks aimed to determine the value of a certain quantity, i.e. to determine a quantitative characteristic of a specific qualitative characteristic (property) of a certain object. Replicate measurements under identical conditions reveal that measurement results differ from one another to varying extent. This is caused by inaccuracy of the measuring system, failure to maintain constant conditions of measurement, and other aspects. Every measurement involves an error. The goal of every measurement is to determine the true value, which is only possible if the error of such measurement is known. An error has a positive value when the measured value is higher than the true (conventional true) value. In estimating the true value, a positive error is subtracted from the measured value (this procedure is referred to as "correction of the measured value")." [2] 
At present, when increasing and greater accuracy of production is required, it is in the area metrology also requires a more accurate expression of the measurement result. Earlier theory of hyb measurement is no longer enough to meet today's requirements, therefore uncertainty measurement theory is increasingly being applied. The aim of this article is to illustrate the system of determining the uncertainty of measurement when evaluating the surface roughness.

\section{Main causes of errors}

- measuring instrument, measuring system (imperfections and unreliability of measuring instruments, such as friction error, errors caused by zero offset, placement error and others);

- method of measurement (failure to account for dynamic properties of measuring instruments, neglecting some functional dependences - indirect measurement);

- conditions under which the measurement is carried out (above all, the temperature error);

- the person who performs and evaluates the measurement (the observer's personal qualities - dexterity, experience, qualification, mental condition, parallax error and limited resolving ability). [3]

\section{Classification of errors}

- by their dependence on time: static, dynamic

- by the possibility of their elimination: errors which can be eliminated and those which cannot

- by type: gross errors, systematic errors, random errors

\section{Uncertainties of measurement and their sources}

An uncertainty is understood to be a parameter which characterizes the range (interval) of values about a measurement result, which can be reasonably attributed to a value of the measurand. It may apply to a measurement result or to readings from instruments, values of constants, corrections, and other aspects on which the uncertainty of a result depends. [2] The basis is the probability principle. Uncertainty of measurement is assumed to cover the true value at an assumed probability (typically $95 \%$ ).

The basic characteristic of uncertainty is standard uncertainty $u$, which is expressed as the value of standard deviation $\mathrm{s}(\mathrm{x})$. At normal distribution, it guarantees the result at a probability of $68.27 \%$. For distributions other than the normal one, it is expressed using the mode or the median. [2] In research and engineering practice, uncertainty of measurement is determined as part of measurement evaluation, such as:

- experimental validation of laws of physics and determination of values of physical constants, definitional measurements, reproduction of units of physical and ordinal quantities and evaluation of metrological properties of primary standards [2];

- calibration of secondary standards and working measuring instruments;

- type tests of measuring instruments and evaluation of their technical and metrological properties;

- evaluation of accurate measurements in testing and product quality inspection, official measurement as defined by the Czech Metrology Act (505/1990 Sb.), and other accurate and obligatory measurements in technical practice, such as acceptance tests and performance guarantee tests, measurement of quantities of substances and energy in economic dealings, measurement of the composition and properties of materials, and other activities. [4]

\section{Theoretical procedure for determining uncertainty of measurement}

A measure of uncertainty of measurement is the standard deviation of the reported quantity. An uncertainty expressed in this manner is referred to as standard uncertainty $\mathrm{u}$, which denotes a range of values around the measured value. Standard uncertainty includes two types: type A standard uncertainty and type B standard uncertainty. They are reported either alone, without a sign, or with a result, in which case they include the \pm sign.

\subsection{Type A standard uncertainty $-u_{a}$}

It is caused by random errors whose causes are generally deemed to be unknown. It is determined from repeated measurements of the same value of measurand under identical conditions. This uncertainty decreases with increasing number of repeated measurements. In addition, random errors are assumed to have a normal distribution. [3]

\subsection{Type B standard uncertainty $-u_{b}$}

It has known causes which can be estimated. They are identified and evaluated by the experimenter. However, they are not always easy to determine. When complex measuring equipment is used and high accuracy is required, the error analysis must be detailed, which demands extensive experience. The sources of uncertainty may be varied. The resulting type B uncertainty is obtained by their summation, regardless of the number of replicate measurements. [3] 


\subsection{Combined standard uncertainty $-u_{c}$}

It is a sum of type A and type B uncertainties. When a measurement result is evaluated using this uncertainty, there is no need to distinguish between type A and type B uncertainties. Combined standard uncertainty specifies an interval which may contain the true value of the measurand at a relatively high probability. This type of uncertainty is preferred in practice. $[3,5]$

\subsection{Expanded standard uncertainty $U$}

It is introduced when a higher probability of correct measurement results is needed. It is obtained by multiplying combined standard uncertainty ucby the coefficient $\mathrm{ku}=2$. The procedures for determining individual standard uncertainties depend on whether the measurement was direct or indirect and whether one or more quantities were measured. The calculated values of coefficients and uncertainties are rounded to three significant digits. The resultant uncertainty is to be rounded to two significant digits. [3, 5] Sources of uncertainties are considered to include all occurrences which have the potential to affect the uncertainty of finding a definite measurement result and which thus increase the difference between the measured value and the true value of a measurand. It is important whether a direct or indirect measurement method is used. Uncertainty is affected by the choice of analogue or digital measuring instruments and by the use of filters, samplers and other devices along the entire path of the measurement signal involving transmission and conditioning. Disturbances from the environment, in the broadest sense, contribute strongly to uncertainty.

\section{Sources of uncertainty}

The most frequent potential sources of uncertainty:

- imperfect or incomplete definition of the measurand or its realization

- incorrect instrument (resolution and other capabilities)

- inadequate (unrepresentative) selection of measurement samples

- inappropriate measurement procedure

- simplified (rounded) constants and values from other sources

- linearization, approximation, interpolation or extrapolation used in evaluation

- unknown or uncompensated effects of environment

- failure to maintain identical conditions for repeated measurements

- subjective effects of the operator

- inaccuracy of standards and reference materials

Some sources affect exclusively, or more strongly, uncertainties evaluated according to one of the types. Many others, however, may cause uncertainties of both types. This scenario poses the greatest risk, as one of the components might be neglected, leading to major distortions.[6,7] A report of uncertainties should include the formulation and notation of resulting values, descriptions of calculation procedures and mandatory information about literature sources. Calculation of uncertainties is an integral part of evaluation of measurement results. Uncertainties must be specified. When expanded uncertainty is reported, the coverage factor $(\mathrm{k})$ used or the corresponding confidence interval must be given. An uncertainty may be reported as absolute or relative, or both. As a rule, uncertainty values are rounded, preferably up, to two significant digits. References to standards used must be included. Some standards set out mandatory elements and formulations for reporting measurement results, including uncertainties. For instance, calibration certificates give the measurement result and expanded uncertainty in the form $(\mathrm{y} \pm \mathrm{U})$ with the following note: "The uncertainty given herein equals two standard deviations. The standard deviation was calculated from the uncertainty of the measurement standard, calibration methods, external effects, short-term effects of the object being calibrated...".[8]

\section{Determination of the true value of uncertainty of measurement}

The guidelines for uncertainties described above were applied to selected surface roughness parameters. These parameters include Ra, Rz, Rv and Rsm. These parameters were chosen on purpose and for several reasons:

- $\mathrm{Ra}-$ it is the most frequently-used roughness parameter

- $\mathrm{Rz}$ - indicates overall height properties of the surface

- $\mathrm{Rv}$ - evaluates the portion of the surface structure which lies below the zero line of the profile, and therefore reflects, for instance, the effects of the stylus size

- Rsm - as the entire article deals with periodic surfaces and this parameter is a basis for setting the roughness measuring machine, it is useful to understand the effects on this parameter as well.

The actual determination of uncertainty involves several steps. 


\subsection{Gross error test}

The first step before calculating uncertainty of measurement involves checking the measured values for gross error. In this case, gross error was considered to be a value larger than \pm 36 . Gross error is a consequence of mistakes in measuring or evaluating a result. Gross errors are either of objective or subjective nature. Since a large error may lead to an inaccurate and incorrect final result, outliers must be excluded from the set of values.

\subsection{Verification of data normality}

In the next step, normal distribution of the measured data had to be verified. The MATLAB program and five statistical tests were employed:

1. Kolmogorov-Smirnov test (kstest)

2. Lilliefors test (lillietest)

3. Jarque-Bera test (jbtest)

4. Student test (ttest)

5. Anderson-Darling (adtest)

In all tests, the null hypothesis was assessed - the instances when it was found true are indicated in tables 6-1 and 62 by the value of 1 . The null hypothesis postulates that the data has a normal distribution. Tables $6-1$ and 6-2 below give examples of results for the RA 6.3 roughness standard and the basic filter under test - Gaussian filter (filter 16610-21). The average, the mode and the median were calculated from the measured data and compared with one another. If they were equal, the data would be very likely to have normal distribution. This comparison together with the outcome of statistical tests is a basis for determining whether the data has a normal distribution or not. All tests were calculated and evaluated for both $2-\mu \mathrm{m}$ and $5-\mu \mathrm{m}$ styluses.

\begin{tabular}{|c|c|c|c|c|}
\hline & Ra & Rz & Rt & Pa \\
\hline $\mathbf{1}$ & 1 & 1 & 1 & 1 \\
\hline $\mathbf{2}$ & 1 & 1 & 0 & 0 \\
\hline $\mathbf{3}$ & 1 & 1 & 1 & 0 \\
\hline $\mathbf{4}$ & 1 & 1 & 1 & 1 \\
\hline $\mathbf{5}$ & 1 & 1 & 1 & 1 \\
\hline MODE & 6.21 & 23.53 & 24.62 & 16.75 \\
\hline MEDIAN & 6.22 & 23.56 & 24.59 & 10.31 \\
\hline AVERAGE & 6.22 & 23.53 & 24.44 & 11.77 \\
\hline
\end{tabular}

Table 1. Table of results of the normal distribution test -2 micrometres

\begin{tabular}{|c|c|c|c|c|}
\hline & Ra & Rz & Rt & Pa \\
\hline $\mathbf{1}$ & 1 & 1 & 1 & 1 \\
\hline $\mathbf{2}$ & 1 & 1 & 0 & 0 \\
\hline $\mathbf{3}$ & 1 & 1 & 0 & 0 \\
\hline $\mathbf{4}$ & 1 & 1 & 1 & 1 \\
\hline $\mathbf{5}$ & 1 & 1 & 1 & 1 \\
\hline MODE & 6.21 & 23.53 & 24.62 & 10.75 \\
\hline MEDIAN & 6.23 & 23.56 & 24.29 & 10.31 \\
\hline AVERAGE & 6.23 & 23.53 & 24.74 & 11.27 \\
\hline
\end{tabular}

Table 2. Table of results of the normal distribution test -5 micrometres

The same test was performed for all values from the roughness standards and for all roughness filters used. The results confirmed that the measured data have a normal distribution and that a calculation according to the above diagram can be used.

\subsection{Type A uncertainty $-u_{a}$}

Type A uncertainty was determined by repeated measurements of roughness of a metrologically traceable surface roughness standard. Given the assumption that uncertainty decreases with increasing number of repeated measurements and existence of random errors with a normal distribution, at least 9 measurement cycles are needed to attain a coverage factor value of $\mathrm{ku}=1$. Therefore, the same number of repeated measurements as in the first test was used. The number of cycles was set at 42 . Type A standard uncertainty must then be calculated from the measured values using relationship (1) or as the mode or median of the measured data. 


$$
u_{a}=s=\sqrt{\frac{\sum_{i=1}^{n}\left(x_{i}-\bar{x}\right)^{2}}{n(n-1)}}
$$

\begin{tabular}{|c|c|c|c|c|c|c|c|}
\hline $\begin{array}{l}\text { Seq. } \\
\text { no. }\end{array}$ & Ra value & $\begin{array}{l}\text { Seq } \\
\text { no. }\end{array}$ & $\begin{array}{c}\text { Ra } \\
\text { value }\end{array}$ & $\begin{array}{l}\text { Seq } \\
\text { no. }\end{array}$ & $\begin{array}{c}\text { Ra } \\
\text { value }\end{array}$ & $\begin{array}{l}\text { Seq } \\
\text { no. }\end{array}$ & $\begin{array}{c}\text { Ra } \\
\text { value }\end{array}$ \\
\hline 1 & 6.1900 & 12 & 6.2800 & 23 & 6.2500 & 34 & 6.2300 \\
\hline 2 & 6.2000 & 13 & 6.1800 & 24 & 6.2200 & 35 & 6.2200 \\
\hline 3 & 6.2400 & 14 & 6.2100 & 25 & 6.2600 & 36 & 6.2600 \\
\hline 4 & 6.2400 & 15 & 6.1900 & 26 & 6.2300 & 37 & 6.2500 \\
\hline 5 & 6.2700 & 16 & 6.2100 & 27 & 6.1700 & 38 & 6.2400 \\
\hline 6 & 6.2700 & 17 & 6.2200 & 28 & 6.2100 & 39 & 6.2200 \\
\hline 7 & 6.2600 & 18 & 6.2100 & 29 & 6.2300 & 40 & 6.2300 \\
\hline 8 & 6.2600 & 19 & 6.2300 & 30 & 6.2400 & 41 & 6.2300 \\
\hline 9 & 6.2900 & 20 & 6.2600 & 31 & 6.2300 & 42 & 6.2200 \\
\hline 10 & 6.2700 & 21 & 6.2800 & 32 & 6.2500 & --- & \\
\hline 11 & 6.2300 & 22 & 6.1800 & 33 & 6.2200 & --- & \\
\hline
\end{tabular}

Table 3. Measured data for RA 0.5 standard, 16610-21 filter and 2-micrometre stylus

$$
u_{a 2}=s=\sqrt{\frac{\sum_{i=1}^{n}\left(x_{i}-\bar{x}\right)^{2}}{n(n-1)}}=\sqrt{\frac{\sum_{i=1}^{n}\left(x_{i}-\bar{x}\right)^{2}}{42(42-1)}}=0,018 \mu \mathrm{m}
$$

\begin{tabular}{|c|c|c|c|c|c|c|c|}
\hline $\begin{array}{l}\text { Seq } \\
\text { no. }\end{array}$ & Ra value & $\begin{array}{l}\text { Seq } \\
\text { no. }\end{array}$ & $\begin{array}{c}\text { Ra } \\
\text { value }\end{array}$ & $\begin{array}{l}\text { Seq } \\
\text { no. }\end{array}$ & $\begin{array}{c}\text { Ra } \\
\text { value }\end{array}$ & $\begin{array}{l}\text { Seq } \\
\text { no. }\end{array}$ & $\begin{array}{c}\text { Ra } \\
\text { value }\end{array}$ \\
\hline 1 & 6.05 & 12 & 6.11 & 23 & 6.08 & 34 & 6.16 \\
\hline 2 & 6.05 & 13 & 6.15 & 24 & 6.16 & 35 & 6.15 \\
\hline 3 & 6.1 & 14 & 6.08 & 25 & 6.09 & 36 & 6.09 \\
\hline 4 & 6.13 & 15 & 6.08 & 26 & 6.05 & 37 & 6.07 \\
\hline 5 & 6.16 & 16 & 6.17 & 27 & 6.13 & 38 & 5.97 \\
\hline 6 & 6.17 & 17 & 6.14 & 28 & 6.1 & 39 & 6.16 \\
\hline 7 & 6.17 & 18 & 6.14 & 29 & 6.11 & 40 & 6.13 \\
\hline 8 & 6.17 & 19 & 6.1 & 30 & 6.13 & 41 & 6.16 \\
\hline 9 & 6.15 & 20 & 6.14 & 31 & 6.16 & 42 & 6.12 \\
\hline 10 & 6.14 & 21 & 6.15 & 32 & 6.14 & --- & \\
\hline 11 & 6.05 & 22 & 6.14 & 33 & 6.14 & --- & \\
\hline
\end{tabular}

Table 4. Measured data for RA 0.5 standard, 16610-21 filter and 5-micrometre stylus

$$
u_{a 5}=s=\sqrt{\frac{\sum_{i=1}^{n}\left(x_{i}-\bar{x}\right)^{2}}{n(n-1)}}=\sqrt{\frac{\sum_{i=1}^{n}\left(x_{i}-\bar{x}\right)^{2}}{42(42-1)}}=0,00452 \mu \mathrm{m}
$$

The $u_{a}$ uncertainty value is sufficient for these calculations and for tests carried out in the next part of this work. The summary in Table 5 shows type A uncertainty values for selected types of roughness parameters using 16610-1 filter.

\begin{tabular}{|c|c|c|c|c|c|c|c|c|}
\hline & Ra-2 & Ra-5 & Rz-2 & Rz-5 & Rv-2 & Rv-5 & Rsm-2 & Rsm-5 \\
\hline RA0.5 & 0.00021 & 0.00025 & 0.0071 & 0.0041 & 0.0034 & 0.0024 & 0.000081 & 0.000054 \\
\hline RA1 & 0.0012 & 0.0011 & 0.0054 & 0.0062 & 0.0031 & 0.0034 & 0.000084 & 0.000022 \\
\hline RA3.2 & 0.00075 & 0.00069 & 0.0033 & 0.0034 & 0.0018 & 0.0017 & 0.000012 & 0.000013 \\
\hline RA6.3 & 0.018 & 0.0045 & 0.048 & 0.045 & 0.019 & 0.016 & 0.00036 & 0.00014 \\
\hline
\end{tabular}

Table 5. Summary of type A uncertainty values for filter 16 610-1

\subsection{Determination of type $B$ uncertainty $-u_{b}$}

Determination of type B uncertainty is much more complicated. The entire process must be analyzed and potential sources of uncertainty in surface roughness measurement identified. The following sources of uncertainty were considered: 
- the value of uncertainty of the machine

- the roughness parameter under evaluation

- the stylus size

Given the automatic measurement cycle of the program, the uncertainty associated with the operator will not be considered, as operator effects are minimized. Furthermore, the effects of environment will be neglected as well because the experiments were carried out in a controlled environment of an accredited testing laboratory (temperature, humidity). Provided that the sources of uncertainty do not correlate, type B uncertainty is determined according to the expression:

$$
u_{b}=\sqrt{\sum_{i=1}^{k}\left(\frac{\partial f}{\partial z_{i}} u_{b_{z i}}\right)^{2}}
$$

Where the sources of uncertainty correlate, the following expression is to be used:

$$
u_{b}=\sqrt{\sum_{i=1}^{k}\left(\frac{\partial f}{\partial z_{i}} u_{b_{z i}}\right)^{2}+\sum_{\substack{i, k=1 \\ i \neq k}} \frac{\partial f}{\partial z_{i}} \frac{\partial f}{\partial z_{k}} u_{b_{z i}} u_{b_{z k}} r_{z_{i k}}}
$$

\subsection{Evaluation of variability of the source}

The measured is a specified quantity which is subject to measurement. An estimate of a quantity is the arithmetic average:

$$
\bar{x}_{j}=\sum_{i=1}^{n} \frac{x_{j}}{n} ; j=1, \ldots m
$$

The output estimate is a measurement result calculated using a functional relationship. The functional relationship between measurands $\mathrm{X} 1, \mathrm{X} 2, \ldots, \mathrm{Xm}$ and the output quantity $\mathrm{Y}$ can be written down explicitly as follows

$$
\mathrm{Y}=\mathrm{f}(\mathrm{X} 1, \mathrm{X} 2, \ldots, \mathrm{Xm})
$$

or implicitly as

$$
\mathrm{f}(\mathrm{Y}, \mathrm{X} 1, \mathrm{X} 2, \ldots, \mathrm{Xm})=0
$$

After denoting the estimates of input quantities with lower-case characters, the following is obtained

$$
y=f(x 1, x 2, \ldots, x m)
$$

or

$$
f(y, x 1, x 2, \ldots, x m)=0
$$

Sample variance of the estimate of the output quantity $\mathrm{Y}$ is defined as

$$
s_{y}^{2}=\sum_{j=1}^{m}\left(\frac{\partial f}{\partial x_{j}}\right)^{2} s_{x j}^{2}+\sum_{j k=1}^{m} \frac{\partial f}{\partial x_{j}} \frac{\partial f}{\partial x_{k}} s_{x j k}(j \neq k)
$$

Where

$$
\begin{gathered}
s_{x j}^{2}=\frac{1}{n(n-1)} \sum_{i=1}^{n}\left(x-\overline{x_{j}}\right)^{2} \ldots \text { sample variance of the sample mean } \overline{x_{j}} \\
\vartheta_{x j}=\frac{1}{n(n-1)} \sum_{i=1}^{n}\left(x-\overline{x_{j}}\right)^{2}\left(x_{k i}-\overline{x_{k}}\right) \ldots \text { sample covariance of sample means } \overline{x_{j}} ; \overline{x_{k}}
\end{gathered}
$$

For calculations with a spreadsheet program, the matrix form is to be used: 


$$
\mathrm{s}_{\mathrm{y}}^{2}=\left(\frac{\partial \mathrm{f}}{\partial \mathrm{x}_{1}} ; \frac{\partial \mathrm{f}}{\partial \mathrm{x}_{2}} ; \ldots ; \frac{\partial \mathrm{f}}{\partial \mathrm{x}_{3}}\right)\left(\begin{array}{cccc}
\vartheta_{\mathrm{x}_{1}}^{2} & \vartheta_{\mathrm{x}_{1,2}} & \ldots & \vartheta_{\mathrm{x}_{1, \mathrm{~m}}} \\
\vartheta_{\mathrm{x}_{2,1}} & \vartheta_{\mathrm{x}_{2}}^{2} & \ldots & \vartheta_{\mathrm{x}_{2, \mathrm{~m}}} \\
\vdots & \vdots & & \vdots \\
\vartheta_{\mathrm{m}, 1} & \vartheta_{\mathrm{x}_{\mathrm{m}, 2}} & & \vartheta_{\mathrm{x}_{\mathrm{m}}}^{2}
\end{array} \mid\left(\begin{array}{c}
\frac{\partial \mathrm{f}}{\partial \mathrm{x}_{1}} \\
\frac{\partial \mathrm{f}}{\partial \mathrm{x}_{1}} \\
\vdots \\
\frac{\partial \mathrm{f}}{\partial \mathrm{x}_{\mathrm{m}}}
\end{array}\right)\right.
$$

The row matrix and column matrix contain conversion coefficients, i.e. partial derivatives of function $\mathrm{f}$ with respect to individual variables calculated for sample means of input quantities $\mathrm{X} 1, \ldots, \mathrm{Xm}$. The measurement result may be written as:

$$
\mathrm{Y}=\overline{\mathrm{y}} \pm 2 \mathrm{~s}_{\mathrm{y}}
$$

A macro constructed in MS EXCEL software was employed to make the evaluation of results more productive and prevent errors during calculation. The calculation of the variability of the source is illustrated in Figure 1. This is the calculation for RA 6.3 standard, a stylus with a $2-\mu \mathrm{m}$ radius and filter 16610-21. The parameter under evaluation was Ra.

\section{Zadávání vstupních dat a výpočet}

\begin{tabular}{|r|c|c|c|c|c|c|}
\hline mëreni & $\mathbf{X} \mathbf{1}$ & $\mathbf{X} \mathbf{2}$ & $\mathbf{X 3}$ & $\mathbf{X} \mathbf{4}$ & $\mathbf{X 5}$ & $\mathbf{X 6}$ \\
\hline 1 & 6,1900 & 6,2500 & & & & \\
\hline 2 & 6,2000 & 6,2200 & & & & \\
\hline 3 & 6,2400 & 6,2600 & & & & \\
\hline 4 & 6,2400 & 6,2300 & & & & \\
\hline 5 & 6,2700 & 6,1700 & & & & \\
\hline 6 & 6,2700 & 6,2100 & & & & \\
\hline 7 & 6,2600 & 6,2300 & & & & \\
\hline 8 & 6,2600 & 6,2400 & & & & \\
\hline 9 & 6,2900 & 6,2300 & & & & \\
\hline 10 & 6,2700 & 6,2300 & & & & \\
\hline 11 & 6,2300 & 6,2200 & & & & \\
\hline 12 & 6,2800 & 6,2600 & & & & \\
\hline 13 & 6,1800 & 6,2500 & & & & \\
\hline 14 & 6,2100 & 6,2400 & & & & \\
\hline 15 & 6,1900 & 6,2200 & & & & \\
\hline 16 & 6,2100 & 6,2300 & & & & \\
\hline 17 & 6,2200 & 6,1200 & & & & \\
\hline 18 & 6,2100 & 6,2200 & & & & \\
\hline 19 & 6,2300 & 6,1800 & & & & \\
\hline 20 & 6,2600 & 6,2200 & & & & \\
\hline
\end{tabular}

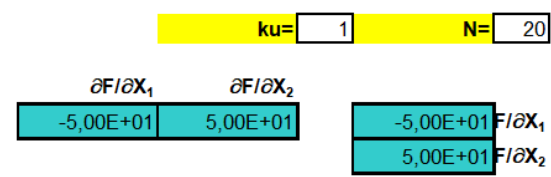

\begin{tabular}{c|l|l|l|l|l|l|} 
Delta & \multicolumn{1}{l}{ X1e } & \multicolumn{1}{l}{ X2e } & \multicolumn{1}{c}{ X3e } & X4e & X5e & X6e \\
\hline & 6,2355 & 6,2215 & & & & \\
\hline
\end{tabular}
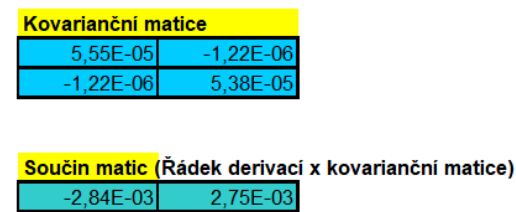

\begin{tabular}{|c|c|c|}
\hline \multicolumn{3}{|c|}{ Konstanty } \\
$\mathrm{U}_{12}$ & $\mathrm{U}_{8}$ & $\Delta \mathrm{U}_{1}$ \\
6,22 & 6,24 & 0,02 \\
\hline
\end{tabular}

Fig. 1. Calculation of the variability of the source

Data processing in MS Excel is performed thanks to recording the measurement data in the column X1, X2, ..,Xn. In each case, 20 measurement cycles are used for calculation. Each column is a record of repeated measurement of roughness. As 20 values were used for evaluation, the coverage factor was set at 1 (this value will change, depending on the amount of data evaluated, see Figure 1). Covariance matrices are then calculated automatically, including their product, variance of values, and the source variability. The same data variability calculation was carried out for $\mathrm{Rz}, \mathrm{Rv}$ and Rsm parameters with all 4 roughness number variants. Table 6 shows results for the $2-\mu \mathrm{m}$ stylus.

\begin{tabular}{|c|c|c|c|c|}
\hline & Ra & Rz & Rv & Rsm \\
\hline RA 0.5 & 0.1 & 0.852 & 0.0358 & 0.0752 \\
\hline RA 1 & 0.137 & 0.477 & 0.0557 & 0.0193 \\
\hline RA 3.2 & 0.176 & 0.778 & 0.0425 & 0.00256 \\
\hline RA 6.3 & 0.529 & 0.984 & 0.207 & 0.0895 \\
\hline
\end{tabular}

Table 6. Variability of the source for selected roughness parameters and 2-micrometre stylus 
Subsequently, expanded uncertainties were evaluated for measurements taken with the 5- $\mu$ m stylus. Results are summarized in Table 7.

\begin{tabular}{|c|c|c|c|c|}
\hline & Ra & Rz & Rv & Rsm \\
\hline RA 0.5 & 0.1 & 0.935 & 0.0751 & 0.109 \\
\hline RA 1 & 0.397 & 0.633 & 0.0142 & 0.501 \\
\hline RA 3.2 & 0.0836 & 0.272 & 0.0819 & 0.268 \\
\hline RA 6.3 & 0.755 & 1.02 & 0.212 & 1.07 \\
\hline
\end{tabular}

Table 7. Variability of the source for selected roughness parameters and 5-micrometre stylus

\subsubsection{Assessment of correlation of the sources of uncertainty}

At first sight, it is not obvious whether the sources of uncertainty chosen for this evaluation correlate. Verification had to be performed using MS Excel. The same data was examined as that used for finding uncertainties ua and U. (see Tables 8 a 9 with example of measured data).

\begin{tabular}{|c|c|c|c|}
\hline Ra-5 & Rz-5 & Rv-5 & Rsm-5 \\
\hline 6.05 & 23.55 & 11.53 & 0.3616 \\
\hline 6.05 & 23.99 & 11.58 & 0.3666 \\
\hline 6.1 & 23.51 & 11.67 & 0.3579 \\
\hline 6.13 & 23.39 & 11.72 & 0.3585 \\
\hline 6.16 & 23.43 & 11.68 & 0.3587 \\
\hline 6.17 & 23.68 & 11.55 & 0.3581 \\
\hline 6.17 & 23.69 & 11.57 & 0.3585 \\
\hline 6.17 & 26.85 & 13.53 & 0.3707 \\
\hline 6.15 & 23.42 & 11.55 & 0.3598 \\
\hline 6.14 & 23.63 & 11.68 & 0.3597 \\
\hline 6.11 & 23.44 & 11.58 & 0.3697 \\
\hline 6.15 & 24.4 & 11.83 & 0.3588 \\
\hline 6.08 & 25.24 & 13.09 & 0.3671 \\
\hline 6.08 & 24.74 & 11.67 & 0.3669 \\
\hline 6.17 & 24.19 & 11.53 & 0.3573 \\
\hline 6.14 & 23.54 & 11.62 & 0.3584 \\
\hline 6.14 & 23.37 & 11.55 & 0.3587 \\
\hline 6.1 & 24.01 & 11.52 & 0.3591 \\
\hline 6.14 & 26.95 & 12.87 & 0.3668 \\
\hline 6.15 & 23.73 & 11.55 & 0.3598 \\
\hline 6.14 & 23.63 & 11.42 & 0.3583 \\
\hline 6.08 & 23.86 & 11.45 & 0.3696 \\
\hline 6.16 & 24.03 & 11.49 & 0.3579 \\
\hline 6.09 & 24.84 & 11.85 & 0.3692 \\
\hline 6.05 & 24.11 & 11.44 & 0.359 \\
\hline 6.13 & 23.91 & 11.38 & 0.3581 \\
\hline$\ldots$ & $\ldots$ & $\ldots$ & $\ldots$ \\
\hline
\end{tabular}

Table 8. List of values for correlation verification, 5micrometre stylus

\begin{tabular}{|c|c|c|c|}
\hline Ra-2 & Rz-2 & Rv-2 & Rsm-2 \\
\hline 6.19 & 23.19 & 11.23 & 0.3649 \\
\hline 6.2 & 23.64 & 11.52 & 0.365 \\
\hline 6.24 & 23.33 & 11.6 & 0.3653 \\
\hline 6.24 & 23.38 & 11.69 & 0.3637 \\
\hline 6.27 & 23.71 & 11.66 & 0.3637 \\
\hline 6.27 & 23.46 & 11.53 & 0.3651 \\
\hline 6.26 & 23.23 & 11.41 & 0.3656 \\
\hline 6.26 & 23.5 & 11.55 & 0.3655 \\
\hline 6.29 & 23.53 & 11.51 & 0.3655 \\
\hline 6.27 & 23.03 & 11.59 & 0.3661 \\
\hline 6.23 & 23.39 & 11.56 & 0.3663 \\
\hline 6.28 & 24.17 & 11.62 & 0.365 \\
\hline 6.18 & 23.7 & 11.61 & 0.3636 \\
\hline 6.21 & 24.07 & 11.6 & 0.3637 \\
\hline 6.19 & 23.77 & 11.49 & 0.3637 \\
\hline 6.21 & 23.45 & 11.47 & 0.3634 \\
\hline 6.22 & 23.08 & 11.39 & 0.3641 \\
\hline 6.21 & 23.64 & 11.43 & 0.3643 \\
\hline 6.23 & 23.53 & 11.57 & 0.3641 \\
\hline 6.26 & 23.39 & 11.31 & 0.3643 \\
\hline 6.25 & 23.44 & 11.32 & 0.3643 \\
\hline 6.22 & 23.8 & 11.43 & 0.3641 \\
\hline 6.26 & 23.75 & 11.45 & 0.3649 \\
\hline 6.21 & 23.68 & 11.37 & 0.3647 \\
\hline 6.23 & 23.7 & 11.42 & 0.3641 \\
\hline 6.23 & 23.87 & 11.5 & 0.3646 \\
\hline$\ldots$ & $\ldots$ & $\ldots$ & $\ldots$ \\
\hline
\end{tabular}

Table 9. List of values for correlation verification, 2micrometre stylus

In Table 10, the resulting value for Ra parameter correlation exceeded the specified non-correlation value $( \pm 0.2)$ several times. Therefore, the measurement and correlation testing was repeated. Results of the repeated measurement are given in Table 11. 


\begin{tabular}{|c|c|c|c|c|}
\hline & Ra-2 & Rz-2 & Rv-2 & Rsm-2 \\
\hline Ra-5 & 0.718944 & 0.08993 & 0.357499 & 0.079061 \\
\hline Rz-5 & 0.1335 & 0.166416 & 0.135515 & -0.06983 \\
\hline Rv-5 & 0.107617 & -0.09113 & 0.15218 & -0.16614 \\
\hline Rsm-5 & -0.06409 & 0.152267 & 0.026345 & 0.246961 \\
\hline
\end{tabular}

Table 10. Values of correlation coefficient

\begin{tabular}{|c|c|c|c|c|}
\hline & Ra-2 & Rz-2 & Rv-2 & Rsm-2 \\
\hline Ra-5 & 0.218944 & 0.18993 & 0.157499 & 0.079061 \\
\hline Rz-5 & 0.1435 & 0.12641 & 0.135515 & -0.06983 \\
\hline Rv-5 & 0.104617 & -0.09113 & 0.15218 & -0.16614 \\
\hline Rsm-5 & -0.08409 & 0.152267 & 0.026345 & 0.246961 \\
\hline
\end{tabular}

Table 11. Values of correlation coefficient

As the assumption of non-correlation of the individual sources of uncertainty was confirmed, substitution into the expression can be performed:

$$
\mathrm{u}_{\mathrm{b}}=\sqrt{\sum_{\mathrm{i}=1}^{\mathrm{k}}\left(\frac{\partial \mathrm{f}}{\partial \mathrm{z}_{\mathrm{i}}} \mathrm{u}_{\mathrm{z}_{\mathrm{i}}}\right)^{2}}
$$

Numerical parameters required for the calculation are summarized in Table 12:

\begin{tabular}{|c|c|c|c|c|}
\hline Sources of uncertainty & Symbol & $\mathbf{U}_{(\mathbf{x b})}$ & $\begin{array}{c}\text { Type of } \\
\text { distribution }\end{array}$ & $\mathbf{K}_{\mathbf{0 . 9 5}}$ \\
\hline Ra-2 parameter & $\mathrm{U}_{\mathrm{Ra} 2}$ & $\mathbf{0 . 5 2 9}$ & Normal & 2 \\
\hline Rz-2 parameter & $\mathrm{U}_{\mathrm{Rz} 2}$ & $\mathbf{0 . 5 2 9}$ & Normal & 2 \\
\hline Rv-2 parameter & $\mathrm{U}_{\mathrm{Rv} 2}$ & $\mathbf{0 . 5 2 9}$ & Normal & 2 \\
\hline Rsm-2 parameter & $\mathrm{U}_{\mathrm{Rsm} 2}$ & $\mathbf{0 . 5 2 9}$ & Normal & 2 \\
\hline Ra-5 parameter & $\mathrm{U}_{\mathrm{Ra} 5}$ & $\mathbf{0 . 7 5 5}$ & Normal & 2 \\
\hline Rz-5 parameter & $\mathrm{U}_{\mathrm{Rz} 5}$ & $\mathbf{0 . 7 5 5}$ & Normal & 2 \\
\hline Rv-5 parameter & $\mathrm{U}_{\mathrm{Rv} 5}$ & $\mathbf{0 . 7 5 5}$ & Normal & 2 \\
\hline Rsm-5 parameter & $\mathrm{U}_{\mathrm{Rsm} 5}$ & $\mathbf{0 . 7 5 5}$ & Normal & 2 \\
\hline calibration value & $\mathrm{U}_{\mathrm{Rkal}}$ & $\mathbf{1 . 0 0 0}$ & Uniform & $\sqrt{3}$ \\
\hline Filter 16610-21 & $\mathrm{U}_{16610-21}$ & $\mathbf{0 . 2 3 4}$ & Normal & 2 \\
\hline Filter 16610-22 & $\mathrm{U}_{16610-22}$ & $\mathbf{0 . 3 0 4}$ & Normal & 2 \\
\hline Filter 16610-31 & $\mathrm{U}_{16610-31}$ & $\mathbf{0 . 2 5 7}$ & Normal & 2 \\
\hline Filter 0601 & $\mathrm{U}_{0601}$ & $\mathbf{0 . 2 4 5}$ & Normal & 2 \\
\hline Filter 4768 & $\mathrm{U}_{4768}$ & $\mathbf{0 . 2 6 7}$ & Normal & 2 \\
\hline
\end{tabular}

Table 12. Summary of standard uncertainties of measurement for selected parameters

The actual calculation, for instance, for Ra parameter and the $2-\mu \mathrm{m}$ stylus, is as follows:

$$
\begin{gathered}
u_{\text {Ra } 2}=\frac{0,529}{2}=0,2645 \mu \mathrm{m} \\
u_{\text {kal }}=\frac{1}{\sqrt[2]{3}}=0,577 \mu \mathrm{m} \\
u_{16610-21}=\frac{0,234}{2}=0,117 \mu \mathrm{m}
\end{gathered}
$$




$$
\mathrm{u}_{\mathrm{b}}=\sqrt{\sum_{\mathrm{i}=1}^{\mathrm{n}} \mathrm{u}_{\mathrm{bi}}^{2}}=\sqrt{0,2464^{2}+0,577^{2}+0,117^{2}}=0,641 \mu \mathrm{m}
$$

Since ua and ub are known, the combined uncertainty of measurement uc can be determined, which includes the effects of both type A and B uncertainties. The following relationship is used:

$$
\mathrm{u}_{\mathrm{c}}=\sqrt{0,00452^{2}+0,641^{2}}=0,62 \mu \mathrm{m}
$$

The above calculation is used for finding the uncertainty for Ras parameter, $2-\mu \mathrm{m}$ stylus and filter 16610-21.

\section{Conclusion}

"Measurement is a set of experimental tasks designed to determine the value of a certain quantity, ie, to determine the quantitative characteristic of a particular qualitative sign (property) of a particular object. The problem of determining the uncertainty of measurement described in this article is, in the meantime, an increasingly important but still neglected process that is necessary to know when expressing the measurement result. Sometime after the measurement uncertainty processing process, each must count down whether it is permissible for the measurement to be measured or not.

\section{Acknowledgments}

This paper was created due to the project GA ZCU v Plzni: SGS-2016-005 "Research and development for innovation in field of Manufacturing processes - Technology of metal cutting II

\section{References}

[1] ČSN EN ISO 13565-3. Geometric Product Requirements (GPS) - Surface Structure: Profile Method; Surfaces having stratified functional properties - Part 3: Elevation characteristics using the probability curve of the material. 1. Brussels: CEN, 2001.

[2] https://web.vscht.cz/ kocourev/files/QA_nejistoty-print.pdf[online]. [cit. 2018-08-10].

[3] Tichá, Š.: (2004) Engineering Metrology: Part 1. 1. Ostrava.

[4] Palenčár, R.: (2001) Uncertainties in Measurement I: Expressing Uncertainty, Automa, page 50

[5] Guide to the Expression of Uncertainty in Measurement (Směrnice pro vyjadřování nejistoty při měření). BIPM, IEC, IFCC, ISO, IUPAC,IUPAP, OIML, 1993

[6] Melichar, M.: Compensation of the touchscreen correction by a contactless method. Pilsen, 2011. Doctoral Thesis (Ph.D.). University of West Bohemia in Pilsen, Faculty of Mechanical Engineering.

[7] Kubátová, D., Melichar, M., Kutlwašer, J. Software filters of surface roughness. Zeszyty naukowe PolitechnikI rzeszowskiej 295, Mechanika 89, 2017, roč. XXXIV, č. 3, s. 333-341. ISSN: 0209-2689

[8] Kubátová, D., Melichar, M., Kutlwašer, J. Impact of stylus size in roughness measurement. In Proceedings of the 28th DAAAM International Symposium. Vienna: DAAAM International, 2017. s. 457-466. ISBN: 978-3-90273411-2, ISSN: 1726-9679 